\title{
International recruitment: individual choice or ethical dilemma?
}

\author{
Amit Malik
}

Specialist Registrar, Nottinghamshire Healthcare NHS Trust; Chair, Collegiate Trainees Committee (CTC) of the Royal College of Psychiatrists, email doctmalik@hotmail.com

\section{I am grateful to International Fellows, WHO officials and members of the Royal College of Psychiatrists for expressing their views at the debate, some of which have been included in this article.}

As far as individual
development is
concerned, the IFP
has helped many
professionals
deal with job
stagnation and
stress, as it has
made them
realise both their
professional and
their monetary
worth.

Telsi he debate on international recruitment gained significant momentum after the International Fellowship Programme (IFP) was set up by the Department of Health. This article summarises some of the issues regarding the policy of the National Health Service (NHS) on the international recruitment of psychiatrists that were raised at the Royal College of Psychiatrists' annual general meeting last summer.

On the one hand, globalisation, world markets in human capital, freedom of movement and individual choice favour international recruitment on a large scale, while on the other hand there are ethical issues concerning the recipient country's responsibility not to damage the healthcare of the donor countries. From the perspective of international recruits, at both trainee and senior levels, the argument for individual choice (in favour of globalisation) is made.

Trainees who come to the UK are often driven out by lack of opportunities in their home countries and simultaneously drawn by the promise of good work experience in the UK. Most countries in the developing world produce more doctors than they can provide postgraduate training for. Access to these postgraduate positions and career progression in general are both poorly defined and often influenced by nepotism. Working conditions and salaries are generally of a comparatively low standard. In contrast, the UK system provides more opportunities, is more merit-based and provides better pastoral care to trainees. Moreover, the UK system pays trainees a living wage.

On the International Fellow level, international recruitment can be mutually beneficial to both the UK system and the donor country. In the donor country, the demand for psychiatrists overseas has made psychiatry a popular specialty and has raised its profile significantly. It has provided professionals with a wider range of clinical experience, especially in areas such as risk assessment and incident reporting. It has also broadened their own experience as trainers through both an experiential process and workshops on training and teaching methods. The diverse nature of services in the UK has provided a template for service development in the donor countries. In addition, these opportunities have led to the development of professional networks, which in turn have been useful in the development of both training and research links between countries. As far as individual development is concerned, the IFP has helped many professionals deal with job stagnation and stress, as it has made them realise both their professional and their monetary worth.

The other major argument in favour of ethical recruitment is globalisation. As travel and communication networks develop, the world is shrinking and people now make choices and decisions about their training and work based on quality and availability rather than simply geographical location. At this stage in the history of medicine, when we expect nothing but the highest professional standards from our doctors, would it be reasonable to expect them not to behave as career-minded professionals and seek the best career opportunities, just as other professionals do? Healthcare professionals are a mobile international workforce and, given the irresistible force of globalisation, it would appear unfair to deny a small group of professionals opportunities for career development based on political boundaries. The world can now be described as a global health community, with international patients travelling all over the world to gain the best balance of quality and cost. Keeping that in mind, it is important to maintain a free flow of healthcare professionals so that there is a better understanding of both cultural nuances and healthcare systems throughout the world.

Countering the above arguments are those opposed to recruitment in the UK of doctors from the developing world. In contrast to the one psychiatrist for every 15000 population in the UK, there is only one psychiatrist for every 250000 population in India or 1000000 population in sub-Saharan Africa. The major note of dissent has been against the active recruitment of well established consultants in low- and middle-income countries. These individuals are clearly highly driven and motivated professionals. This is exemplified by their willingness to move country mid-stage in their careers, which represents an even bigger loss to the donor country. These countries are thereby deprived of doctors in their prime, who have held senior positions and been responsible for teaching, clinical work and policy advice. The loss is, thus, not only restricted to healthcare delivery but extends to the profession as a whole.

This naturally raises major issues with regard to the four ethical cornerstones of the medical profession, namely: autonomy (here, individual versus 
societal autonomy); justice (for all); beneficence; and non-malfeasance. The above arguments in favour of international recruitment produce an inherent conflict between the autonomy of professionals and wider society, towards which they have some responsibility. They also pose pertinent questions about justice for all, especially in the most deprived countries. The principles of beneficence and non-malfeasance, when extended to a societal perspective, also suggest a strong case for providing benefit to and not causing harm to communities as a whole. Some points of view would suggest that this is what occurs when healthcare professionals migrate for their individual benefit.

The criticism is mainly systemic and seems to be directed largely towards the Department of Health, but also, to a certain degree, towards the Royal Colleges and the governments of the donor countries for their complicity in the systemic asset stripping of these already deprived societies. Professional migration is not a new phenomenon but it has increased massively in recent years in response to policy development in recipient countries, and donor countries have consequently seen an exodus of the middle generations of professionals.

Various measures have been proposed and implemented by donor and host countries to mitigate the effects of this exodus. Some countries train their doctors in the local language, which also helps to retain them. This may not be the most progressive solution to the problem, but more realistic solutions have also been proposed. These include financial reparation to the donor country, an obligation on doctors to spend a certain amount of time in the public health service in the donor country, and improvement in training and employment conditions in both developing and developed countries. There has also been pressure on developed countries to restrict immigration from certain deprived countries. The Department of Health has made a start in this direction by having a code of ethics to guide its international recruitment, but its critics suggest that success has been merely symbolic, owing to the complicity of governments of developing nations like India. A process of reciprocal recognition of qualification may help redress the longer-term imbalance, as a significant number of doctors would like to go back to work in their own countries but find it difficult to do so, because of the lack of parallel recognition of qualifications obtained in a different training system.

The issue needs to be debated in international forums such as the World Health Organization and the United Nations. It is not in the interests of either the professionals who have migrated or the host country to keep the debate going. The governments in the donor countries have not been particularly proactive in addressing the conflict. In these circumstances the onus to keep the debate alive is on professional organisations like the Royal Colleges and the General Medical Council.

For contributions to this column, please contact Brian Martindale FRCPsych, Early Intervention in Psychosis Service, South Tyne and Wearside NHS Mental Health Trust, Monkwearmouth Hospital, Newcastle Road, Sunderland SR5 1NB, email Brian.Martindale@stw.nhs.uk

\section{International Associates}

The introduction of membership of the College's International Divisions via the title of 'International Associates' has attracted considerable interest. Since January 2005, II psychiatrists have been accepted in this role, which allows them to be active in their respective International Divisions and receive all the publications of the College that members receive. More details can be found on the College website at http://www.rcpsych.ac.uk/members/membership/ about.htm

\section{Volunteer schemes for senior psychiatrists and specialist registrars}

Our database is now up and running, and there are a good number of experienced colleagues willing to offer their expertise. We hope that the database will now become known throughout the International Divisions and will be of considerable assistance to services lacking specific types of experience and knowledge. Full details of both schemes are available on the College website at http://www.rcpsych.ac.uk/ college/spcomm/bia/senior.htm

\section{International Divisions at the College annual meeting in Glasgow, 10-13 July 2006}

For the first time, all six International Divisions of the College will have their own sessions at the College meeting in 2006 and there will be a joint session of the College and the World Psychiatric Association (WPA) involving the Presidents of the two organisations.
Some countries

train their doctors

in the local

language, which also helps to retain

them.

\section{A process of reciprocal \\ recognition of qualification}

may help ... as a significant number of doctors would like to go back to work in their own countries but find

it difficult to do

so.
On the volunteer schemes, see the report by Andrew

Sims and Ruth

Sims on page 18 of this issue 